\title{
Distribution of insertion sequence IS200 in Salmonella and Shigella
}

\author{
ISIDRE GIBERT, ${ }^{1}$ JORDI BARBÉ $^{1}$ and JOSEP CASADESÚS ${ }^{2 *} \dagger$ \\ ${ }^{1}$ Departament de Genètica i Microbiologia, Universitat Autònoma de Barcelona, 08193 Bellaterra, Barcelona, Spain \\ ${ }^{2}$ Departamento de Genética, Universidad de Sevilla, Apartado 1095, 41080 Sevilla, Spain
}

(Received 9 July 1990; revised 3 August 1990; accepted 24 August 1990)

\begin{abstract}
Two DNA probes for the detection of insertion sequence IS200 by either Southern blotting or colony hybridization were constructed. One of the probes is a $300 \mathrm{bp} E c o \mathrm{RI}$-HindIII fragment of IS200 cloned onto pBluescript $\mathrm{KS}(+)$; the other is a tail-to-tail dimer of the same fragment cloned onto pUC19. A survey of the presence of IS200 among enteric bacteria revealed that more than $90 \%$ of the pathogenic or food-poisoning isolates of Salmonella spp. examined contained one or more copies of insertion sequence IS200, with the exception of the subgenus I serovar S. agona in which IS200 is not found. Although insertion sequence IS200 was first considered a Salmonellaspecific element, it also exists in many isolates of Shigella sonnei and Shigella flexneri, but not in Shigella dysenteriae.
\end{abstract}

\section{Introduction}

Insertion sequence IS 200 is a transposable element of some $700 \mathrm{bp}$, found in Salmonella typhimurium but not in Escherichia coli; in turn, $E$. coli insertion elements IS1-4 are not present in Salmonella (Lam \& Roth, 1983a). The chromosome of the standard, wild-type strain $S$. typhimurium LT2 contains six copies of IS200; moreover, one insertion mutation caused by IS200 is known: hisD984: : IS200 (Lam \& Roth, $1983 a, b$ ). Molecular analysis of this mutation unveiled several interesting features of the element: (1) it does not contain inverted repeats; (2) upon insertion, it does not generate duplication of host DNA sequences; (3) it is absolutely polar, at least in one orientation, because of the presence of a strong, rhoindependent terminator (Lam \& Roth, 1986). Despite intensive efforts, hunts for new insertion mutants in Salmonella have been unsucessful and insertion elements other than IS200 have not been found (Casadesús \& Roth, 1989). Lack of insertion mutants in Salmonella clearly differs from the situation found in $E$. coli, where many spontaneous polar mutations are caused by endogenous insertion sequences (Galas \& Chandler, 1989). Thus IS elements seem to be more abundant and active in $E$. coli than in Salmonella and to behave distinctively in their contribution to spontaneous mutagenesis (Casadesús \& Roth, 1989; Galas \& Chandler, 1989).

$†$ Present address: Abteilung Mikrobiologie, Biozentrum, Universität Basel, Klingelbergstrasse 70, CH-4056 Basel, Switzerland.
The existence of genus-specific insertion elements such as IS200 might have important consequences, both theoretical and practical. From an evolutionary point of view, it would suggest that the element originated after species isolation and has, therefore, a recent origin (Roth \& Schmid, 1981; Lam \& Roth, 1983b; Casadesús \& Roth, 1989). Moreover, the fact that $E$. coli and Salmonella do not share ancestral insertion elements may suggest that these are ultimately eliminated from the genome. For practical purposes, genus-specific elements like IS200 might be useful as molecular probes for the identification of clinical isolates. However, this paper describes a survey on the presence of IS200 among natural (clinical or food-poisoning) isolates of enteric bacteria and presents a more complex picture. The survey was carried out by Southern hybridization, using IS 200 probes specifically constructed for this study. We show that insertion element IS200 exists not only in Salmonella, but has also an erratic distribution among isolates of Shigella flexneri and Shigella sonnei.

\section{Methods}

Bacterial strains, plasmids and phages. Laboratory strains of Salmonella typhimurium and Escherichia coli used in this study are listed in Table 1. Clinical and food-poisoning isolates of Salmonella and Shigella were kindly provided by the following laboratories and hospitals: Laboratori Municipal de Microbiologia (Barcelona, Spain), Hospital Santa Creu i Sant Pau (Barcelona, Spain), Hospital del Mar (Barcelona, Spain), Centro Ramón y Cajal (Madrid, Spain) and Department of Pathology, University of Utah (Salt Lake City, Utah, USA). Natural 
Table 1. Bacterial strains

\begin{tabular}{|c|c|c|}
\hline Designation & Genotype or phenotype & Reference or source \\
\hline $\begin{array}{l}\text { Salmonella typhimut } \\
\text { SV380 } \\
\text { TR6249 }\end{array}$ & $\begin{array}{l}\text { his } \triangle 9533 / \text { pNK } 75 \\
\text { hisD } 984: \text { : IS } 200\end{array}$ & $\begin{array}{l}\text { This study } \\
\text { Lam \& Roth (1983a) }\end{array}$ \\
\hline $\begin{array}{l}\text { Escherichia coli } \\
\text { DH } 5 \alpha\end{array}$ & $\begin{array}{l}\phi 80 \mathrm{~d} \text { lacZ } \triangle \mathrm{M} 15 \text { end } A 1 \text { rec } A 1 \text { hsdR17 supE44 } \\
\text { thi-1 gyrA relAI } \mathrm{F}^{-} \Delta(\operatorname{lac} Z Y A-\arg F)\end{array}$ & Lab. collection \\
\hline
\end{tabular}

* Derived from the standard wild-type LT2.

isolates of E. coli, Citrobacter, Enterobacter, Klebsiella, Serratia and Proteus were collected from various sources, including the public institutions mentioned above.

Plasmid pNK 75 is a pBR333 derivative containing the hisO/P region and the his $G$ and hisD genes of Salmonella typhimurium (Foster et al., 1981). pBluescript $\mathrm{KS}(+)$, an $\mathrm{Amp}^{\mathrm{r}} \mathrm{LacZ}^{+}$derivative of ColE1, is a product of Stratagene Cloning Systems (Grand-Lancy, France). pUC19 (Ampr LacIZ $^{+}$) is a pBR322-M13mp19 hybrid (YanischPerron $e t$ al., 1985). Plasmids pIZ43, pIZ45 and pIZ46, all constructed for this study, are described below; the prefix pIZ has been registered at the Plasmid Reference Center (Stanford University, Palo Alto, California, USA).

The transducing phage P22 HT105/1 int 201 was derived by G. Roberts (unpublished results) from P22 HT105/1 (Schmieger, 1971). P22 H5 is a clear-plaque mutant used to test phage sensitivity by crossstreaking.

Culture media and growth conditions. Nutrient broth (Difco) was the rich medium used for laboratory strains. Natural isolates of enteric bacteria were grown in brain-heart infusion medium (Adsa Micro, Barcelona, Spain). The E medium of Vogel \& Bonner (1956) supplemented with $0.2 \%$ glucose was used as minimal medium. For solid media, Difco agar was added at a concentration of $1.5 \%(w / v)$. Nutritional supplements, when needed, were used according to Davis et al. (1980). Ampicillin and tetracycline, both from Sigma, were used at $50 \mathrm{mg} \mathrm{l}^{-1}$ and $20 \mathrm{mg} \mathrm{l}^{-1}$, respectively (for rich media). Histidinol plates contained adenine and thiamin (Johnston \& Roth, 1979). Green plates were prepared according to Chan et al. (1972). All cultures were grown at $37^{\circ} \mathrm{C}$.

Genetic methods. Procedures for phage growth, transduction, purification of transductants and isolation of phage-free clones were according to Davis et al. (1980). Transformation of $E$. coli DH5 $\alpha$ with plasmid DNA followed the procedures described by Maniatis et al. (1982).

DNA techniques. Plasmid DNA was isolated by the alkaline extraction procedure of Birnboim \& Doly (1979) and purified by banding in a CsCl/ethidium bromide gradient (Maniatis et al., 1982). Chromosomal DNA extraction followed the procedures described by Wilson (1987). Restriction enzymes, T4 DNA ligase and alkaline phosphatase were purchased from Boehringer Mannheim and used as recommended by the supplier. Restriction fragments were separated in $0.8 \%$ agarose (Sigma) gels and recovered using the GeneClean system (Bio 101). DNA denaturation, transfer of DNA from agarose gels to Millipore nitrocellulose filters, prehybridization and hybridization were according to Southern (1975) and Maniatis et al. (1982). DNA probes were labelled by one of the following procedures: (1) nicktranslation and ${ }^{32}$ P]dATP labelling; (2) chemiluminescent labelling with the ECL system (Amersham). The 32-mer 5'TAAATATCCTCCGGCATAGCCGAGCTTTTTCA $3^{\prime}$ was obtained from D. R. Hillyard, University of Utah (Salt Lake City, Utah, USA). ${ }^{32} \mathrm{P}$ labelling and purification of oligonucleotides followed the procedures of Chaconas \& van de Sande (1980). All hybridizations were carried out under highly stringent conditions. For autoradiography, a DuPont Cronex intensifying screen and a Valca AFW polyester film were used. For colony hybridization, colonies were grown overnight on Millipore nitrocellulose filters placed upon nutrient broth plates; hybridization followed the procedures of Hanahan \& Meselson (1980).

\section{Results}

\section{Construction and use of IS200 probes}

The probe used in former studies on IS200 was a derivative of $\mathrm{M} 13 \mathrm{Hol} 76$ containing the insertion hisD984:: IS200 (Lam \& Roth, 1983a). Albeit useful, DNA probes based on M13Hol76 may cause a number of undesirable complications. For instance, M13Hol76 contains some $4 \mathrm{~kb}$ of the promoter-proximal region of the Salmonella typhimurium histidine operon; these chromosomal sequences can obviously complicate the hybridization pattern of restriction fragments. This problem is usually overcome by the isolation and labelling of an internal IS200 fragment (i.e. the $0.3 \mathrm{~kb}$ EcoRI-HindIII fragment: see Lam \& Roth, 1986). However, the existence of an additional $E c o$ RI site in the hybrid phage DNA (Lam \& Roth, 1986; Casadesús \& Roth, 1989) makes the isolation tedious. Handling of M13Hol76 in genetic experiments also has specific limitations, since it can only infect F-containing strains and has no selectable markers. To overcome these limitations we constructed new IS 200 probes on plasmid vehicles.

The first plasmid constructed, pIZ43, is a pNK75 derivative containing IS200. pIZ43 was constructed in vivo, moving the chromosomal his $D 984$ : : IS200 insertion into plasmid pNK 75 by homologous recombination at the flanking his sequences. All genetic crosses involved P22-mediated transduction. The strategy for these crosses was similar to that of Lam \& Roth (1983a). A physical and genetic map of plasmid pIZ43 is shown in Fig. 1.

For use as a probe, pIZ43 has several advantages over 

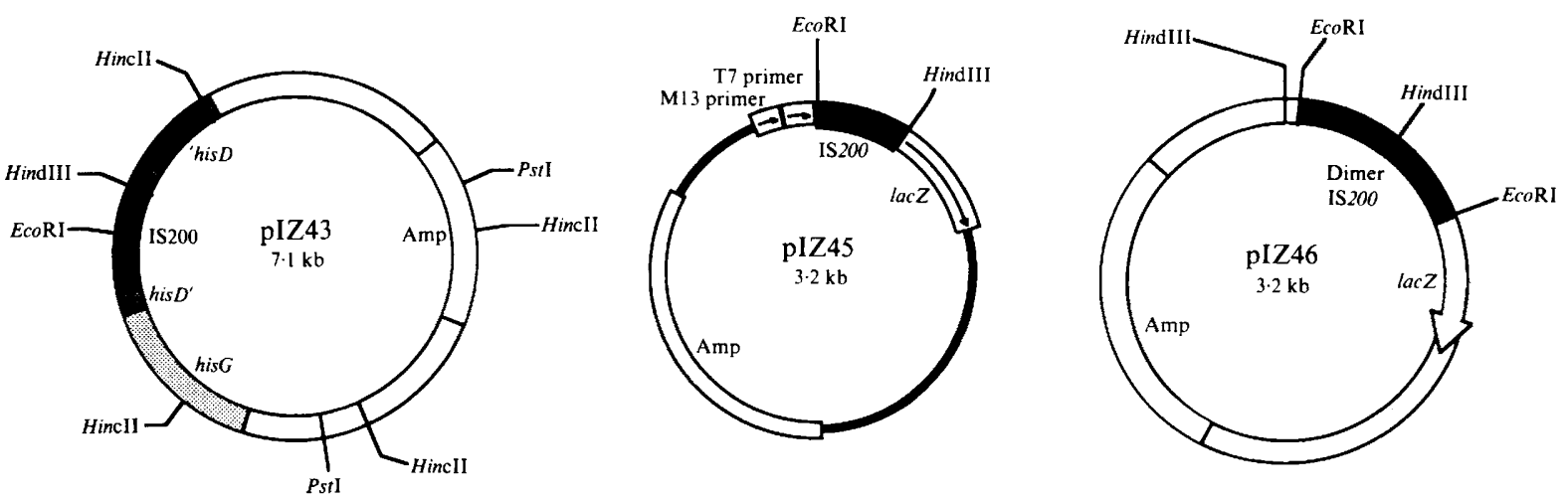

Fig. 1. Genetic and physical maps of plasmids pIZ43, pIZ45 and pIZ46. Only relevant restriction sites are shown. The maps are not drawn to scale.

M13Hol76: for instance, it is amplifiable and contains a selectable marker $\left(A m p^{r}\right)$. However, it still carries the same his sequences present in $\mathrm{M} 13 \mathrm{Hol} 76$ and generates a number of EcoRI-HindIII fragments. To construct a plasmid vehicle devoid of chromosomal sequences other thän IS200, we subcloned the internal EcoRI-HindIII fragment of IS200 onto pBluescript KS(+). The resulting plasmid, pIZ45, contains the internal, $0.3 \mathrm{~kb} E c o \mathrm{RI}-$ HindIII fragment of IS200 and no his sequence (Fig. 1). An additional advantage is that the size of pIZ45 is less than half that of pIZ43.

Radioactive labelling of the $0.3 \mathrm{~kb}$ EcoRI-HindIII fragment of pIZ45 provides an excellent substrate for both Southern blotting and colony hybridization. If genomic DNA is digested with a restriction enzyme that does not cut within IS200, such as PvuII or AvaI (Casadesús \& Roth, 1989; Lam \& Roth, 1986), the number of IS200 copies present in the DNA tested can be read directly as the number of hybridization bands observed in the autoradiography. With non-radioactive labelling procedures, clear-cut Southern patterns were only obtained when the number of hybridization bands was low $(<10)$. For higher copy numbers, double digestion of genomic DNAs or comparison between blottings carried out on independent PvuII and AvaI digests were often necessary. Conversely, colony blotting with non-radioactive probes only provided unambiguous results when the copy number was higher than 3-4.

To overcome these limitations, we constructed a probe that might give stronger hybridization, thus being more appropriate for use both in Southern hybridization and in colony blotting with weaker, non-radioactive labelling procedures. The probe, a tail-to-tail dimer of the EcoRIHindIII fragment of IS200, is carried on plasmid pIZ46, a pUC19 derivative (Fig. 1). The dimer can be easily isolated by gel electrophoresis as a $0.6 \mathrm{~kb} E c o$ RI fragment. When the dimer is labelled by the ECL procedure, the hybridization signal provided by each
IS200-containing restriction fragment is amplified by serial annealing between surplus probe DNA and the free portion of formerly hybridized dimers (in a 'Christmas-tree drawing' fashion). Preliminary data suggest that this procedure might be suitable for routine identification of clinical isolates, where non-radioactive labelling is a crucial advantage. However, all the surveys summarized below were carried out using ${ }^{32} \mathrm{P}$-labelled probes (either monomeric or dimeric).

\section{Survey of the presence of IS200 elements in clinical isolates of Salmonella}

Over 100 Salmonella isolates, belonging to the four Salmonella subgenera (Brenner, 1984), were screened for the presence of IS200. Many of these isolates were pathogenic strains of human or veterinary origin; a few had been isolated as food-poisoning strains of unknown pathogenicity. Southern hybridization assays, summarized in Table 2, revealed the presence of one or more IS200 elements in the vast majority of Salmonella isolates examined. The number of IS 200 copies varied greatly among strains, even within the same subgenus or serovar. On average, the highest numbers of IS200 elements were found in $S$. typhi (10-25 copies). Only 17 out of 142 isolates did not contain IS200. Interestingly, 14 of these 17 isolates belong to the same serovar, $S$. agona, included in subgenus I (Brenner, 1984). This is the only serovar where IS200 is absent; negative strains are also found among isolates of subgenus III ( $S$. arizonae), but the majority of $S$. arizonae strains appear to contain IS 200 (some harbouring up to 14 copies of the element).

\section{Survey of the presence of IS200 in natural isolates of enteric bacteria other than Salmonella}

The same methods as described above were applied to the analysis of DNA from E. coli (19 strains), Citrobacter 
Table 2. Distribution of insertion sequence IS200 among natural isolates of Salmonella

\begin{tabular}{lrl}
\hline \hline \multicolumn{1}{c}{ Organism } & $\begin{array}{c}\text { No. of } \\
\text { isolates tested }\end{array}$ & \multicolumn{1}{c}{ No. of IS200 copies* } \\
\hline S. typhimurium & 25 & $1(1), 4(3), 6(6), 7(3), 10(5), 11(5), 12(2)$ \\
S. typhi & 15 & $10(2), 14(3), 15(1), 17(4), 20(4), 25(1)$ \\
S. paratyphi $A$ & 5 & $4(1), 6(1), 11(3)$ \\
S. schottmuelleri & 5 & $2(3), 6(1), 7(1)$ \\
S. enteritidis & 18 & $1(8), 2(1), 3(6), 4(3)$ \\
S. hirschfeldii & 2 & $4(1), 8(1)$ \\
S. pullorum & 2 & $2(2)$ \\
S. arizonae & 26 & $0(3), 2(4), 7(7), 8(1), 9(2), 10(1), 12(3), 13(1), 14(4)$ \\
S. choleraesuis & 2 & $2(2)$ \\
S. gallinarum & 6 & $1(1), 2(2), 4(3)$ \\
S. abony & 1 & $2(1)$ \\
S. azteca & 1 & $1(1)$ \\
S. derby & 2 & $5(2)$ \\
S. essen & 1 & $3(1)$ \\
S. fyris & 1 & $2(1)$ \\
S. grampian & 1 & $4(1)$ \\
S. kentucky & 1 & $11(1)$ \\
S. montevideo & 4 & $2(1), 3(3)$ \\
S. panama & 2 & $3(1), 5(1)$ \\
S. tilburg & 2 & $2(2)$ \\
S. salamae & 2 & $4(2)$ \\
S. virchow & 2 & $1(1), 2(1)$ \\
S. agona & 14 & $0(14)$ \\
S. houtenae & 2 & $3(2)$ \\
\hline \hline
\end{tabular}

* $X(Y): X$ is the number of copies of the sequence, while $Y$ is the number of isolates harbouring that number.

freundii (4 strains), Enterobacter aerogenes (5 strains), Klebsiella pneumoniae (2 strains), Serratia marcescens (6 strains) Proteus mirabilis (10 strains), Shigella flexneri (5 strains), Shigella sonnei (3 strains) and Shigella dysenteriae (5 strains). Surprisingly, two isolates of Shigella flexneri and one of $S$. sonnei proved to contain 1-4 copies of IS200. One band of weak hybridization, which might suggest the existence of a related, partly homologous sequence, was also observed in all strains of Shigella dysenteriae. A similar result was obtained by Lam \& Roth (1983a) using a laboratory strain of $S$. dysenteriae. All the remaining strains of enteric species gave negative results, indicating that these genera do not contain IS 200 or related, partly homologous elements.

To confirm the presence of IS200 among natural isolates of Shigella spp., over sixty additional isolates of clinical origin were tested. The results, shown in Table 3 , can be summarized as follows: (1) many isolates of $S$. sonnei and $S$. flexneri proved to contain 1-4 copies of IS200; (2) IS200 was absent from all the $S$. dysenteriae isolates tested; (3) one or two weak hybridization bands were found in certain isolates of $S$. dysenteriae, suggesting the existence of a related sequence. To ascertain whether any of the hybridization bands observed was due to the presence of IS630, a Shigella IS element that shows homology to one IS200 end (Matsutani et al., 1987), we carried out Southern hybridization analysis using a 5'-32 P-labelled 32-mer homologous to the left end of both IS630 and IS200 (Lam \& Roth, 1986; Matsutani et al., 1987). Genomic DNAs were digested with AvaI, an endonuclease that does not cut IS200 or IS630 (Casadesús \& Roth, 1989; Matsutani et al., 1987). With

Table 3. Distribution of insertion sequences IS200 and IS630 among natural isolates of Shigella

\begin{tabular}{lcll}
\hline \hline Organism & No. of isolates tested & \multicolumn{1}{c}{ No. of IS200 copies*† } & \multicolumn{1}{c}{ No. of IS630 copies* } \\
\hline S. flexneri & 27 & $0(11), 1(2), 3(6), 4(8)$ & $4(6), 5(6), 6(15)$ \\
S. sonnei & 35 & $0(15), 1(1), 2(1), 3(11), 4(7)$ & $3(1), 4(1), 5(20), 5(2), 6(4),>10(7)$ \\
S. dysenteriae & 10 & $0(3), 1 ?(5), 2 ?(2)$ & $0(10)$ \\
\hline \hline
\end{tabular}

- $X(Y): X$ is the number of copies of the sequence; $Y$ is the number of isolates harbouring that number.

$\dagger$ Number of hybridization bands observed with the EcoRI-HindIII central fragment of IS200 (monomeric or dimeric) as the probe.

$¥$ The number of IS630 copies is calculated as the number of hybridization bands observed using the 32-mer as the probe minus the number of hybridization bands observed using the EcoRI-HindIII central fragment of IS200 as the probe. 
this procedure, the number of hybridization bands increased in many $S$. sonnei and $S$. flexneri DNAs, but not in Salmonella DNAs included as a control. We believe that the number of bands obtained for each Shigella genomic DNA hybridized against the 32-mer is the sum of IS630 and IS200 copies present (Table 3). Hybridization with the 32-mer was also observed in $S$. sonnei DNAs that did not hybridize with the EcoRIHindIII fragment of pIZ45, suggesting that these strains carry IS 630 but not IS 200 . All the $S$. sonnei and $S$. flexneri strains tested proved to contain IS630, while IS 200 was only found in $16 / 27 \mathrm{~S}$. flexneri and 20/35 S. sonnei isolates. Shigella strains carrying IS200 but not IS630 were not found. No hybridization with the 32-mer was found in S. dysenteriae; thus, the origin of the weak hybridization band obtained with the internal EcoRIHindIII fragment of IS200 is unknown.

\section{Discussion}

Within the family Enterobacteriaceae, the genera Escherichia, Shigella, Citrobacter and Salmonella from a closely related group, with Klebsiella and Enterobacter as more distant relatives (Brenner, 1984). Escherichia coli and the four species of Shigella might be even considered a single species on the basis of DNA relatedness (Brenner et al., 1977; Brenner, 1984). E. coli and Salmonella typhimurium have almost identical chromosome structure, as defined by gene order (Ochman \& Wilson, 1977; Roth \& Schmid, 1981). Their DNA sequences have drifted apart about $58 \%$ in silent sites (Ochman \& Wilson, 1977) but only $15 \%$ in total (Brenner et al., 1977; Crawford et al., 1980). Genetic transfer between $E$. coli and $S$. typhimurium occurs easily; actually, exchange of genetic information is likely to occur between all members of the family Enterobacteriaceae, thereby defining a single genetic pool (Jones \& Sneath, 1970). However, despite their incomplete genetic isolation, these bacterial genera have clearly diverged in one aspect: the possession of IS elements. Many ISs seem to be totally or partly confined within a genus, species or serovar. For instance, IS200 exists in Salmonella but not in E. coli, while Salmonella does not contain any of the E. coli elements IS $1-4$ (Lam \& Roth, 1983a). Other ISs have more erratic distribution patterns, probably caused by horizontal proliferation of the element; for instance, IS2 exists in E. coli $\mathrm{K} 12$ and E. coli $\mathrm{B}$ as well as in Shigella and Klebsiella, but not in E. coli C (Galas \& Chandler, 1989).

In the case of IS200, this paper shows that the element is extremely common among natural isolates of Salmonella, with the exception of the serovar $S$. agona. This suggests that the element originated in Salmonella and has spread within salmonellae, probably by vertical proliferation. IS200 is absent from all other enteric species examined, with the exception of certain isolates of Shigella sonnei and Shigella flexneri. Both the percentage of strains harbouring IS200 and the average number of IS200 copies are higher in Salmonella than in Shigella, suggesting that the element has a more recent history in the latter. An obligate speculation is that it may have been introduced into Shigella by horizontal transfer from Salmonella. Interestingly, Shigella sonnei and $S$. flexneri are closely related to $E$. coli, where IS 200 is not found. The absence of IS 200 from the $E$. coli genome is unlikely to be caused by genetic isolation: using Fprimes, the element can be transferred from Salmonella typhimurium to laboratory strains of $E$. coli $\mathrm{K} 12$, but the introduction of the element is not followed by transposition in its new host (J. Casadesús, unpublished). However, increase of IS200 copy number has been observed in Salmonella strains grown under specific conditions (Lam \& Roth, 1983a; J. Casadesús, unpublished).

Given the existence of horizontal genetic flow among enteric species, the absence of an IS from a potential host may indicate that this host fails to provide cellular ancillary functions required for transposition. Thus, unlike $E$. coli $\mathrm{K} 12$, certain Shigella isolates may have allowed establishment of IS200 after horizontal transfer. The observation that IS200 is only found in Shigella isolates that also contain the partly homologous element IS630 suggests two alternative possibilities: (1) IS630 might provide ancillary functions that would enable IS200 to transpose in Shigella. (2) IS630 and IS200 may be members of the same iso-IS family; ancillary functions necessary to transpose might be common for both elements. Experimental evidence favouring either of these explanations is not yet available.

For practical purposes, IS200 might be a suitable probe to identify clinical isolates of Salmonella with relatively high accuracy (more than $90 \%$ of the isolates classified as salmonellae by other criteria prove to carry the sequence). ECL labelling of the dimer probe cloned onto pIZ46 should easily allow identification by colony blotting. However, the presence of IS200 in many Shigella strains hampers a safe, unambiguous identification. Double-check tests using a second probe based on one of the Shigella insertion elements that do not exist in the Salmonella genome (i.e. use of a central IS630 fragment) will probably be necessary. Such a system is now being developed in our laboratory.

This work was supported in part with funds from the DGUI of the Regional Government of Andalusia (Junta de Andalucía), whose generous funding is acknowledged. The collaboration of Joaquín Ruiz in blotting experiments is greatly appreciated. We are also grateful to John Roth, Nancy Kleckner, Guillem Prats, José Luis San Millán and David Hillyard for providing strains and to Sebastián Chávez for 
critical reading of the manuscript. The technical assistance of Asuncion Blasco and José Córdoba is also appreciated.

\section{References}

BirNBoIM, H. C. \& Doly, J. (1979). A rapid alkaline extraction procedure for screening recombinant plasmid DNA. Nucleic Acids Research 7, 1513-1523.

BRENNER, D. J. (1984). Enterobacteriaceae. In Bergey's Manual of Systematic Bacteriology, pp. 408-420. Edited by N. R. Krieg \& J. G. Holt. Baltimore \& London: Williams \& Wilkins.

Brenner, D. J., Fanning, G. R., Steigerwalt, A. G., Sodd, M. A. \& DoctoR, B. P. (1977). Conservation of transfer ribonucleic acid and 5S ribonucleic acid cistrons in Enterobacteriaceae. Journal of Bacteriology 129, 1435-1439.

Casadesús, J. \& Roth, J. R. (1989). Absence of insertions among spontaneous mutants of Salmonella typhimurium. Molecular and General Genetics 216, 210-216.

Chaconas, G. \& van De SANDE, J. H. (1980). $5^{\prime}{ }^{32}$ P-labeling of RNA and DNA restriction fragments. Methods in Enzymology 65, 75-88.

Chan, R. K., Botstein, D., Watanabe, T. \& OGata, Y. (1972). Specialized transduction of tetracycline by phage P22 in Salmonella typhimurium. II. Properties of a high frequency transducing lysate. Virology 50, 883-898.

Crawford, I. P., Nichols, B. P. \& Yanofsky, C. (1980). Nucleotide sequence of the trpB gene in Escherichia coli and Salmonella typhimurium. Journal of Molecular Biology 142, 489-502.

Davis, R. W., BotsteIN, D. \& Roth, J. R. (1980). Advanced Bacterial Genetics. Cold Spring Harbor, New York: Cold Spring Harbor Laboratory.

Foster, T., Davis, M. A., Takeshita, K., Roberts, D. E. \& KLECKNER, N. (1981). Genetic organization of transposon Tn 10 . Cell 23, 201-213.

GaLAS, D. J. \& CHANDLER, M. (1989). Bacterial insertion sequences. In Mobile DNA, pp. 109-162. Edited by D. E. Berg \& M. M. Howe. Washington, DC. American Society for Microbiology.

Hanahan, D. \& Meselson, M. (1980). Plasmid screening at high colony density. Gene 19, 147-151.
Johnston, M. H. \& Roth, J. R. (1979). Histidine mutants requiring adenine: selection of mutants with reduced hisG expression in Salmonella typhimurium. Genetics 92, 1-15.

JONES, D. \& SNEATH, P. A. H. (1970). Genetic transfer and bacterial taxonomy. Bacteriological Reviews 34, 40-81.

LAM, S. \& ROTH, J. R. (1983a). IS200: a Salmonella-specific insertion sequence. Cell 34, 951-960.

LAM, S. \& RoTH, J. R. (1983b). Genetic mapping of IS200 copies in Salmonella typhimurium strain LT2. Genetics 105, 801-811.

LAM, S. \& RoTH, J. R. (1986). Structural and functional studies on insertion element IS200. Journal of Molecular Biology 187, 157-167.

Maniatis, T., Fritsch, E. F. \& Sambrook, J. (1982). Molecular Cloning: A Laboratory Manual. Cold Spring Harbor, New York: Cold Spring Harbor Laboratory.

Matsutani, S., Othsubo, H., Maeda, Y. \& Othsubo, E. (1987). Isolation and characterization of IS elements repeated in the bacterial chromosome. Journal of Molecular Biology 196, 445-455.

OCHMAN, H. \& WILSON, A. C. (1987). Evolutionary history of enteric bacteria. In Escherichia coli and Salmonella typhimurium: Cellular and Molecular Biology, pp. 1649-1654. Edited by F. C. Neidhardt. Washington, DC: American Society for Microbiology.

RoTH, J. R. \& SCHMID, M. B. (1981). Arrangement and rearrangement of the bacterial chromosome. Stadler Symposia 13, 53-69.

SCHMIEGER, H. (1971). A method for the detection of phage mutants with altered transducing ability. Molecular and General Genetics 110, 378-381.

SOUTHERN, E. M. (1975). Detection of specific sequences among DNA fragments separated by gel electrophoresis. Journal of Molecular Biology 98, 503-517.

VOGEL, H. G. \& BONNER, D. M. (1256). Acetylornithase of E. coli: partial purification and some properties. Journal of Biological Chemistry 218, 97-106.

WILSON, K. (1987). Preparation of genomic DNA from bacteria. In Current Protocols in Molecular Biology, pp. 2.4.1-2.4.2. Edited by F. M. Ausubel, R. Brent, R. E. Kingston, D. D. Moore, J. D. Seidman, J. A. Smith \& K. Struhl. New York; Wiley.

YanisCh-PERRON, C., VieIRA, J. \& Messing, J. (1985). Improved M13 phage cloning vectors and host strains: nucleotide sequences of the M13mp18 and pUC19 vectors. Gene 33, 103-119. 